\title{
Differences in Skill Loss During Unemployment Across Industries and Occupations
}

\author{
Victor Ortego-Marti* \\ University of California Riverside
}

This version: July 27, 2017

\begin{abstract}
Starting with Ljungqvist and Sargent (1998) and Pissarides (1992), the search and matching literature has found that skill loss occurring during unemployment has important effects on macroeconomic models of unemployment. This paper presents some evidence that the rate of skill loss varies across occupations and industries. Occupations and industries that require more skills experience higher rates of human capital decay. These findings have important implications for models of equilibrium unemployment, in particular for mismatch unemployment and the optimal reallocation of workers across sectors.
\end{abstract}

JEL Classification: E24.

Keywords: Search and matching; unemployment; loss of skills; unemployment history; human capital decay; mismatch unemployment.

\footnotetext{
*Department of Economics, University of California Riverside. Sproul Hall 3132, Riverside CA 92521. Email: victor.ortego-marti@ucr.edu. Phone: 951-827-1502. I am grateful to Jang-Ting Guo and Alwyn Young for helpful conversations.
} 


\section{Introduction}

There is abundant evidence in the labor literature on the negative effects of unemployment on workers' wages and productivity. ${ }^{1}$ Motivated by this empirical fact, Ljungqvist and Sargent (1998) and Pissarides (1992) find that human capital decay during unemployment has important implications for the macroeconomy. Pissarides (1992) shows that unemployment becomes more persistent when unemployed workers lose skills during unemployment. In Ljungqvist and Sargent (1998), human capital decay combined with labor market policies accounts for the high unemployment rates in Europe compared to the US.

Since then, the search and matching literature has extensively explored the effect of skills loss during unemployment. With regards to policy, Pavoni (2011), Pavoni and Violante (2007) and Shimer and Werning (2006) study the effect of skills decay on the optimal unemployment insurance. Coles and Masters (2000) compare the effectiveness of training programs and job creation subsidies in reducing long-term unemployment. Charlot and Decreuse (2001) analyze how skill decay affects workers' search effort and hazard rates. Skills decay affect a number of labor market and aggregate outcomes. Ortego-Marti (2016b) and Tjaden and Wellschmied (2014) show that search frictions and human capital decay can account for most of the observed residual wage dispersion. Labor market fluctuations are also larger in models with human capital decay, as Lalé (2017) and Ortego-Marti (2016a) show. Ortego-Marti (2015) finds large TFP differences among OECD countries due to search frictions and loss of skills. Finally, recent work by Jarosch (2015) studies the role of job insecurity and loss of skills in explaining the experience of job displaced workers.

This paper provides some empirical evidence that the rate of skills loss varies across industries and occupations using the Panel Study of Income Dynamics (PSID). Overall, as intuition would suggest, occupations and industries that require more skills experience the largest losses.

\footnotetext{
${ }^{1}$ See Davis and von Wachter (2011) and the references therein for an overview of the results from the job displacement literature. Using US Social Security data, Davis and von Wachter (2011) find that displaced workers' earnings drop by around 30\% upon separation, and remain around $15 \%$ to $20 \%$ below the control group 20 years after displacement. Results are similar in Germany, see Jarosch (2015). Edin and Gustavsson (2008) use Swedish data on test scores and find that one full year of non-employment is associated with a loss of the equivalent of 0.7 years of schooling. Further evidence on human capital decay due to breaks in production are found in the provision of health services and in jobs involving routine tasks such as data entry, mechanical assembly and car radio production, see Bailey (1989), David and Brachet (2011), Hockenberry and Helmchen (2014), and Shafer, Nembhard, and Uzumeri (2001).
} 
The rate of skills loss is around 3 times larger for workers employed as professionals, technical workers, sales workers, managers and officials, compared to workers employed as craftsmen, foremen and operatives. Similarly, workers employed in retail, FIRE (finance, insurance and real estate), business and personal services and public administration sectors see skills losses that are almost twice as large as losses in the other industries (mining, construction, manufacturing and transport).

These results have important implications for the labor market and the aggregate economy. Different rates of skills decay give rise to differences across sectors of the economy (where sectors are either occupations or industries) in terms of wage dispersion, labor market volatility and long-term unemployment. More importantly, the results affect the optimal reallocation of workers across sectors. As Şahin, Song, Topa, and Violante (2014) show, mismatch unemployment arises if sectors have different matching efficiencies, as the central planner would prefer to place more unemployed workers in sectors (i.e. industries or occupations) with high matching efficiency, other things equal. ${ }^{2}$ When skills loss varies across sectors, the social planner prefers to have fewer workers waiting in unemployment in sectors or occupation with higher losses. This changes the social planner's optimal allocation of workers and the amount of mismatch. ${ }^{3}$

\section{Empirical Evidence}

This section uses the PSID waves from 1968 to 1997, a large panel of US workers, to estimate skills losses by industry and occupation. The PSID asks workers how many weeks they were unemployed in the previous year. Similar to Ortego-Marti (2016b) and Ortego-Marti (2015), I use the answers to this question to construct the variable Unhis, which contains workers' accumulated unemployment spells in months, i.e. their unemployment history, as this is the relevant variable in models with search and skills loss. The empirical estimation focuses on men between 18 and 65 years of age to avoid labor market participation decisions, as these are usually absent in these models. As is standard in the literature, the estimation excludes

\footnotetext{
${ }^{2}$ When productivity varies across sectors, the central planner wants more unemployed workers in sectors with higher matching efficiency and in sectors with higher productivity. The optimal rule balances these two objectives.

${ }^{3}$ Search models with skills loss are inefficient even when the Hosios-Mortensen-Pissarides condition holds, as there is an additional externality besides the usual congestion externality. Firms do not internalize that by posting more vacancies they reduce unemployment duration and improve the economy's productivity. See Laureys (2014).
} 
self-employed workers and workers in farming or in the army. Overall the estimation is based on around 42,000 observations and 4,500 individuals.

The following regression model is ran by occupation and industry

$$
\log w_{t}=\delta U n h i s_{t}+\beta X_{t}+\varepsilon_{t},
$$

where $X$ includes the usual controls in Mincerian regressions, namely education controls (some high school, high school, some college, college and postgraduate), a cubic in potential experience, race controls, regional dummies and year fixed effects. ${ }^{4}$ The results are robust to alternative specifications common in Mincerian regressions. There might be some concern that the estimated coefficient $\hat{\delta}$ captures losses incurred from changing occupations, so for robustness I consider the alternative regression model

$$
\log w_{t}=\delta \text { Unhis }_{t}+\gamma \operatorname{docc}_{t}+\beta X_{t}+\varepsilon_{t}
$$

where docc is a dummy variable for whether there was a change in occupation. This variable captures any effect stemming from changes in occupations and thus addresses the above mentioned concern.

Table 1 reports the results for occupations and Table 2 for industries. In each table, columns (1) and (2) correspond to the regression models (1) and (2). The robust standard errorsclustered at the worker level - are reported in brackets. The results show that skills losses vary significantly by occupation and industry. In terms of occupation, monthly losses range from $2.18 \%$ for managers and officials to $0.4 \%$ for operatives. Not surprisingly, workers employed as managers and officials, and in professional, technical, clerical and sales occupations have average monthly losses of $1.89 \%$, whereas the average monthly loss for workers employed as craftsmen, foremen and operatives is $0.62 \%$. Occupations that in general require more skills, and for which we would expect higher human capital losses due to unemployment, experience human capital losses that are three times larger than occupation requiring fewer skills. At the more disaggregated 2-digit level, the professions with higher losses include physicians and other

\footnotetext{
${ }^{4}$ When the regression is run by occupations one can add industry controls, and vice versa. The results barely change. The results are very similar with a worker fixed effects regression model, and when other controls such as married or number of children are included.
} 
workers in the medical field, accountants, teachers, architects, chemists, engineers, airplane pilots, management advisors, photographers, public relations, lawyers and similar occupations. By contrast, professions with lower losses include typists, clerical workers, receptionists, foremen, police workers, firemen, transport equipment operatives and so on.

As Table 2 shows, differences at the industry level are also significant. Skills losses in wholesale and retail trade, FIRE (finance, insurance and real estate), business and personal services, and public administration and government are on average almost twice as large as the average loss in mining, construction, manufacturing, and transportation, communications and utilities sectors. Differences in loss of skills are more prominent in occupations, consistent with findings in Kambourov and Manovskii (2009) that occupation specific human capital seems more important than industry specific human capital.

To provide more evidence that the loss of skills per occupation and industry are statistically different, I run a pooled regression of log wages on unemployment history, the same controls $X$ as in (1) and (2), and add occupation controls and their interaction with unemployment history, and similarly in a separate regression for industry sectors. I then calculate the F-test for the null hypothesis that the coefficients on the interactions of occupation and unemployment history are all equal (and similarly for the regression with industry controls). The F-statistics are $\mathrm{F}(4,4555)$ with a value of 9.10 for the interaction with occupations, and $\mathrm{F}(7,4253)$ with a value of 3.71 for the interaction with industries. Both reject the null of same effect comfortably at even the $1 \%$ level.

\section{Implications for models of equilibrium unemployment}

The above results have implications for models of equilibrium unemployment. Besides generating differences in wage dispersion, unemployment persistence and labor market volatility per sector of the economy (where sectors can be defined at the occupation or industry level), an interesting implication is that different rates of skills loss may affect the optimal allocation of workers across sectors (i.e. industries or occupations). ${ }^{5}$

As Şahin et al. (2014) show, some misallocation of workers arises when sectors have different matching efficiencies, meaning that in some sectors the same number of unemployed workers and firms lead to more matches - matching efficiency can be interpreted as the equivalent of

\footnotetext{
${ }^{5}$ For simplicity, I follow Şahin et al. (2014) and use sector to refer either to occupations or industries.
} 
the productivity parameter $A$ in a production function $Y=A F(K, L)$. Other things equal, the social planner would prefer to have unemployed workers waiting in sectors with high matching efficiency. Mismatch unemployment corresponds in this setting to the amount of unemployment caused by this misallocation. When sectors differ in their productivity, the social planner has an added incentive to allocate more workers where productivity is higher. Şahin et al. (2014) show that the planner's optimal allocation takes into account these two effects and equates the vacancy unemployment ratio across sectors, weighting each ratio by their productive and matching efficiency. Mismatch unemployment is the distance between the social planner's optimal allocation and the observed allocation, which they can measure using available information on unemployment and vacancies per occupation and industry.

With different skills losses across sectors, the optimal allocation changes. The social planner prefers to place more unemployed workers in sectors that have high matching efficiency and a low skills depreciation rate during unemployment. In some way this problem is similar to the case with productivity differences across sectors, except that now productivity is endogenous and depends on how many unemployed workers are searching, as they affect the matching rate and unemployment duration. Placing more unemployed workers in a sector now increases unemployment duration and lowers productivity, thus introducing a trade-off for the planner. Therefore, there is an added composition effect that changes the solution to the planner's problem. The optimal allocation balances the two objectives of the planner. Whether mismatch increases or decreases with differences in skills loss depends on how losses correlate with matching efficiency. If skills losses are larger in occupation/sectors with low matching efficiency, mismatch will be higher. Otherwise, mismatch may decrease.

\section{Conclusion}

This paper provides some empirical evidence that the rate of skills loss varies across occupations and sectors. Occupations that require more skills experience three times larger skills losses during unemployment than the remaining occupations. For industries associated with more skilled workers, skills losses are twice as large than industries associated with less skilled workers. These differences in the rate of skills decay during unemployment have important implications for equilibrium models of unemployment. In particular, they affect the optimal allocation of workers across sectors and the amount of observed mismatch unemployment. 


\section{References}

Bailey, C. D., 1989. Forgetting and the learning curve: A laboratory study. Management science 35 (3), 340-352.

Charlot, O., Decreuse, B., 2001. Can skill decay increase search effort? Economics Letters $71(3), 359-362$.

Coles, M., Masters, A., 2000. Retraining and long-term unemployment in a model of unlearning by not doing. European Economic Review 44 (9), 1801 - 1822.

David, G., Brachet, T., 2011. On the determinants of organizational forgetting. American Economic Journal: Microeconomics 3 (3), 100-123.

Davis, S. J., von Wachter, T. M., 2011. Recessions and the cost of job loss. NBER Working Paper No. 17638.

Edin, P.-A., Gustavsson, M., 2008. Time out of work and skill depreciation. ILR Review 61 (2), 163-180.

Hockenberry, J. M., Helmchen, L. A., 2014. The nature of surgeon human capital depreciation. Journal of Health Economics 37, 70-80.

Jarosch, G., 2015. Searching for job security and the consequences of job loss. Mimeo, Stanford University.

Kambourov, G., Manovskii, I., 2009. Occupational specificity of human capital. International Economic Review 50 (1), 63-115.

Lalé, E., 2017. Loss of skill and labor market fluctuations. Labour Economics.

Laureys, L., 2014. The cost of human capital depreciation during unemployment. Bank of England Working Paper No. 505.

Ljungqvist, L., Sargent, T. J., 1998. The european unemployment dilemma. Journal of Political Economy 106 (3), 514-550.

Ortego-Marti, V., 2015. Loss of skill during unemployment and TFP differences across countries. Mimeo, UC Riverside.

Ortego-Marti, V., 2016a. The cyclical behavior of unemployment and vacancies with loss of skills during unemployment. Macroeconomic Dynamics, 1-28.

Ortego-Marti, V., 2016b. Unemployment history and frictional wage dispersion. Journal of Monetary Economics 78, 5- 22.

Pavoni, N., 2011. Optimal unemployment insurance, with human capital depreciation, and duration dependence. International Economic Review.

Pavoni, N., Violante, G. L., 2007. Optimal welfare-to-work programs. Review of Economic Studies 74 (1), 283-318. 
Pissarides, C. A., 1992. Loss of skill during unemployment and the persistence of employment shocks. Quarterly Journal of Economics 107 (4), pp. 1371-1391.

Şahin, A., Song, J., Topa, G., Violante, G. L., 2014. Mismatch unemployment. American Economic Review 104 (11), 3529-3564.

Shafer, S. M., Nembhard, D. A., Uzumeri, M. V., 2001. The effects of worker learning, forgetting, and heterogeneity on assembly line productivity. Management Science 47 (12), 1639-1653.

Shimer, R., Werning, I., April 2006. On the optimal timing of benefits with heterogeneous workers and human capital depreciation. Mimeo, University of Chicago.

Tjaden, V., Wellschmied, F., 2014. Quantifying the contribution of search to wage inequality. American Economic Journal: Macroeconomics 6 (1), 134-161. 
Table 1: Effects of Unemployment History on Wages By Occupation

\begin{tabular}{lcc}
\hline \hline Occupation & $(1)$ & $(2)$ \\
\hline Professional, technical & -0.0182 & -0.0177 \\
& $(0.003)$ & $(0.003)$ \\
Managers, officials & -0.0218 & -0.0208 \\
Clerical, sales & $(0.0027)$ & $(0.0027)$ \\
& -0.0168 & -0.0164 \\
Craftsmen, foremen & $(0.0022)$ & $(0.0021)$ \\
& -0.0083 & -0.0078 \\
Operatives & $(0.0014)$ & $(0.0013)$ \\
& -0.004 & -0.0039 \\
& $(0.0014)$ & $(0.0014)$ \\
\hline
\end{tabular}

Note.- Brackets report the robust standard errors with worker id clusters. 
Table 2: Effects of Unemployment History on Wages by Sector

\begin{tabular}{lcc}
\hline \hline & $(1)$ & $(2)$ \\
\hline Mining & -0.0076 & -0.0079 \\
Construction & $(0.0041)$ & $(0.0042)$ \\
& -0.0088 & -0.0085 \\
Manufacturing & $(0.0021)$ & $(0.00203)$ \\
& -0.0066 & -0.0062 \\
Transport, Comm., Utilities & $(0.0013)$ & $(0.0013)$ \\
& -0.0085 & -0.0085 \\
Wholesale, Retail Trade & $(0.0030)$ & $(0.0029)$ \\
& -0.0181 & -0.0170 \\
FIRE & $(0.0020)$ & $(0.0019)$ \\
Business, Personal Services & -0.0134 & -0.0130 \\
& $(0.0032)$ & $(0.0032)$ \\
Public Admin., Government & -0.0138 & -0.0135 \\
& $(0.0021)$ & $(0.0021)$ \\
& -0.0144 & -0.0136 \\
& $(0.0035)$ & $(0.0034)$ \\
\hline
\end{tabular}

Note.- Brackets report the robust standard errors with worker id clusters. 